\title{
The development of hardness homogeneity in aluminum and an aluminum alloy processed by ECAP
}

\author{
Cheng Xu • Terence G. Langdon
}

Received: 1 June 2006/ Accepted: 28 August 2006/Published online: 4 January 2007

(C) Springer Science+Business Media, LLC 2006

\begin{abstract}
Equal-channel angular pressing (ECAP) is an effective fabrication process for obtaining ultrafinegrained materials. This paper examines the development of homogeneity in materials processed by ECAP with emphasis on samples of pure aluminum and an Al-6061 alloy processed by ECAP for up to 8 passes at room temperature. The Vickers microhardness was recorded on the polished cross-sectional planes of each as-pressed billet and the results are plotted in the form of contour maps to provide a pictorial depiction of the hardness distributions throughout the cross-sections. The factors influencing the homogeneity are examined, including the die corner angle within the ECAP die and the number of imposed passes. It is shown that good homogeneity may be achieved through ECAP processing when the number of passes in ECAP is reasonably high.
\end{abstract}

\section{Introduction}

Severe plastic deformation (SPD) has become attractive in recent years because it provides the capability of achieving remarkable grain refinement, typically to the submicrometer or even the nanometer level, and thus it often leads to superior mechanical properties [1]. Numerous investigations have been performed

C. Xu $(\bowtie) \cdot$ T. G. Langdon

Departments of Aerospace \& Mechanical Engineering and Materials Science, University of Southern California, Los Angeles, CA 90089-1453, USA

e-mail: chengxu@usc.edu concerning various aspects of SPD processing, with the mechanical properties examined from the macro-scale to nano-indentation and with the investigations covering a wide range from conventional microstructural examinations to atomistic simulations of the deformation mechanisms. Research work on SPD has also been extended to cover a wide range of materials including metallic alloys and composites.

The most attractive, and potentially the most useful, SPD technique appears to be equal-channel angular pressing (ECAP) [2] where a rod is pressed through a die constrained within a channel which is bent through an abrupt angle, $\Phi$, and with a corner curvature angle, $\Psi$, as shown schematically in Fig. 1 [3]. There are two distinct advantages in using ECAP processing. First, it has the potential for producing large bulk samples, sufficient for industrial applications, without the introduction of any porosity or contaminants. Second, it is a simple processing technique that has the capability of being developed into a continuous processing procedure [4]. Processing by ECAP leads to significant strengthening of the material at ambient temperatures $[5,6]$ and, provided the ultrafine grains have a reasonable thermal stability, to the occurrence of superplastic ductilities at high strain rates at elevated temperatures $[7,8]$.

The success of the ECAP technique in achieving ultrafine-grained microstructures and advanced properties leads to concerns and interest in the development of homogeneity in materials processed by ECAP, especially when these materials have a potential for use in industrial applications. Under ideal conditions, it is calculated and confirmed that a sample pressed through an ECAP die will undergo a homogeneous simple shear strain [9-11]. However, it is important to 


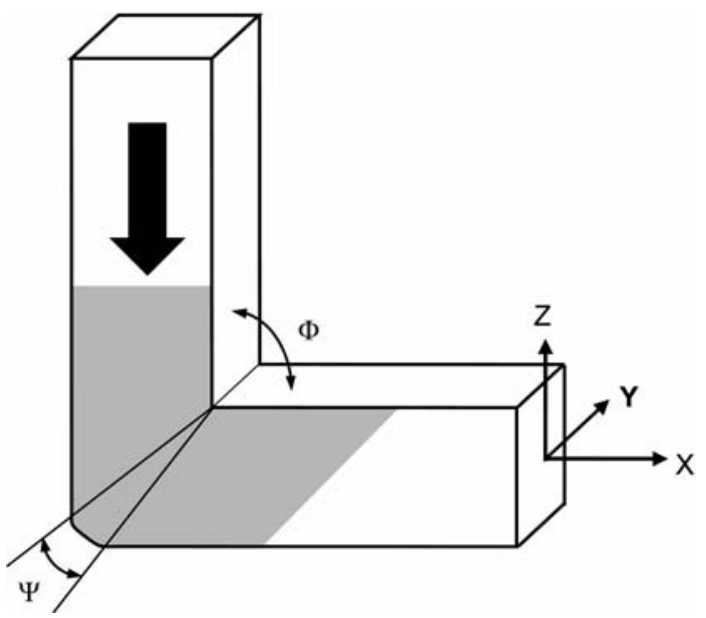

Fig. 1 Schematic illustration of ECAP showing the $X, Y$ and $Z$ directions

recognize that in practice the applied strain during ECAP is not homogeneous. For example, there is a frictional force between the sample and the die wall and this may change the strain distribution especially in the vicinity of the die walls.

This paper examines the development of homogeneity in samples processed by ECAP by taking hardness measurements across the whole cross-sectional plane of samples subjected to ECAP, corresponding to measurements on the $X$ plane in Fig. 1, and by evaluating the significance of homogeneity development as a function of the die corner angle, $\Psi$, and the number of passes in ECAP. As will be demonstrated, materials initially become inhomogeneous after a single pass of ECAP but thereafter they evolve so that there is the development of an essentially homogeneous microstructure with increasing numbers of passes except only in a very small area in the vicinity of the bottom surface.

\section{Influence of the die corner angle, $\psi$}

Much interest has focused on the homogeneity of materials processed by ECAP, primarily on the effect of the die configuration and especially the die angle $\Phi$ and the corner angle $\Psi$. It is well established that the strain achieved through a single pass of ECAP is related only to the die angles $\Phi$ and $\Psi$ under ideal conditions [10]. Therefore, it is important to evaluate the effect of the corner angle $\Psi$ because most of the investigations conducted to date use a die with a channel angle of $\Phi=90^{\circ}$ where this angle is selected because it is most effective in achieving an ultrafinegrained microstructure [12].
Experiments were conducted using specimens of high purity $\mathrm{Al}$ (99.99\%) and with two different ECAP facilities: (1) a solid die made of tool steel with the channels having circular cross-sections and $\Psi=20^{\circ}$ and (2) a split die, also made of tool steel, consisting of two parts with the channel machined into the polished face of one part with a square cross-section and with $\Psi=0^{\circ}$ [3]. The samples of pure $\mathrm{Al}$ were processed by ECAP at room temperature for up to a total of 4 passes using route $B_{C}$ where the sample is rotated by $90^{\circ}$ in the same direction between each pass [13]. Microhardness measurements were taken on the cross-sectional surfaces of the as-pressed samples, where this is perpendicular to the pressing or $X$ direction in Fig. 1, and the values of the Vickers microhardness, $\mathrm{Hv}$, were recorded in a regular grid pattern with spacings between each measurement of $\sim 0.5 \mathrm{~mm}$. By comparison, the microhardness indentations had sizes in the range of $\sim 40-50 \mu \mathrm{m}$. The values measured for $\mathrm{Hv}$ were plotted in the form of contour maps to depict the variations of the local hardness over the cross-sectional planes as shown in Fig. 2a for the as-pressed sample using the solid die with $\Psi=20^{\circ}$ and in Fig. $2 b$ for the as-pressed sample using the split die with $\Psi=0^{\circ}$.

The average microhardness, calculated by averaging the values of the individual measurements for each sample, was $\sim 43.2$ for pure $\mathrm{Al}$ subjected to 4 passes of ECAP via route $B_{C}$ using the solid die with $\Psi=20^{\circ}$ and $\sim 42.1$ for ECAP through four passes using the split die with $\Psi=0^{\circ}$, respectively. By comparison, the hardness value was $\sim 18$ for the sample in the unpressed condition, thereby showing that the as-pressed values are both significantly larger after ECAP and essentially independent of the value of $\Psi$. The contour maps for the as-pressed samples using two different die configurations show a reasonable homogeneity of the microhardness value distributions over the entire crosssectional planes in these two conditions although there is some inhomogeneity in a small area in the vicinity of the bottom surfaces of the samples where the microhardness values are lower than the average. It is apparent from Fig. 2 that this inhomogeneous area tends to cover a slightly larger fraction of the crosssectional surface in the sample pressed using the split die with $\Psi=0^{\circ}$.

The inhomogeneities observed at the lower surfaces of the billets are attributed to the development of a shearing zone during ECAP. In principle, the channel within the ECAP die is bent through $90^{\circ}$ and the shear strain is applied to the sample along a sharp and welldefined shear plane lying at $45^{\circ}$ with respect to the $X$ axis and corresponding to the abrupt transition between the two parts of the channel. In practice, 
Fig. 2 Contour maps showing the Vickers microhardness distribution in the crosssection of pure aluminum billets subjected to ECAP for 4 passes via route $B_{C}$ using a a solid die with $\Psi=20^{\circ}$ and $\mathbf{b}$ a split die with $\Psi=0^{\circ}$
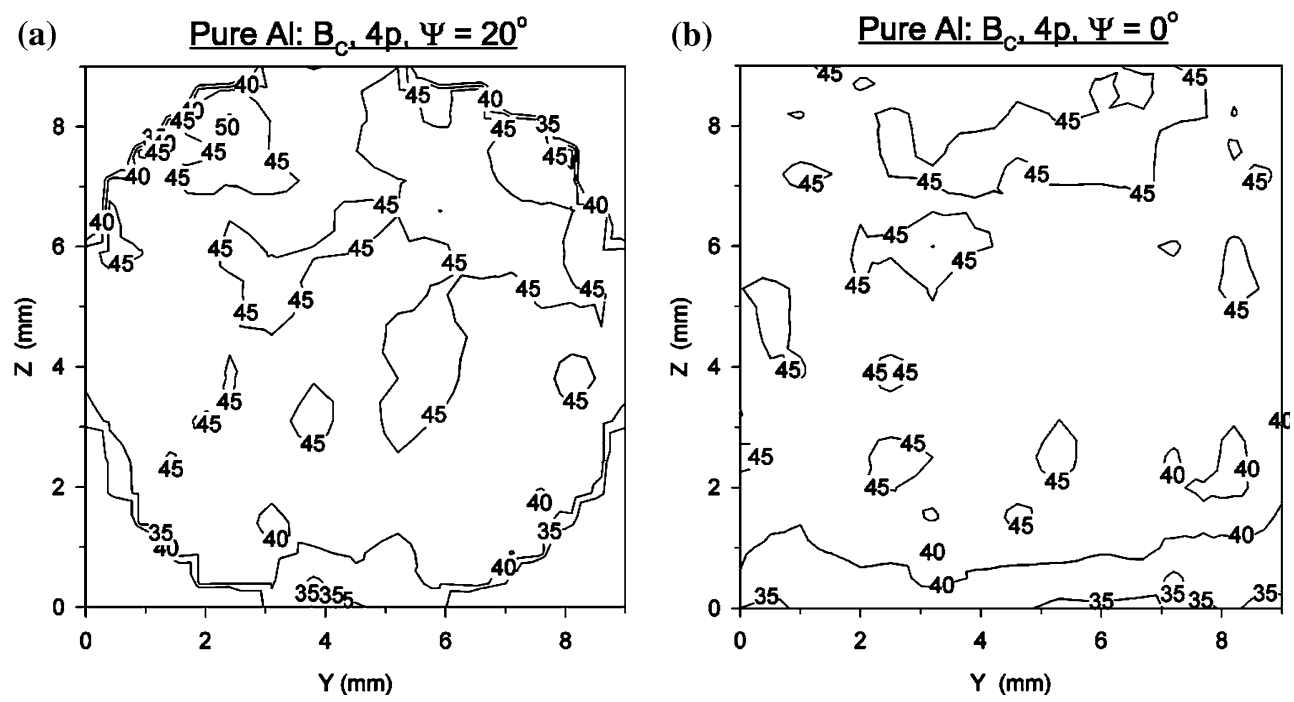

however, it is well established that the use of an ECAP die with a sharp corner having an arc of curvature of $\Psi=0^{\circ}$ leads to the occurrence of a "dead zone" at this outer corner where the billet is no longer in contact with the die wall [11, 14-18]. Although the problems associated with these dead zones can be alleviated or removed through the use of dies having movable die walls $[19,20]$, the construction of these dies is not easy and therefore their use tends to be inconvenient and time-consuming. In practice, therefore, conventional dies where the die walls are fixed are generally more practical for use in ECAP processing.

Another important finding from Fig. 2 is that the inhomogeneous layer covers a slightly larger area in the sample pressed using a sharp corner die with $\Psi=0^{\circ}$ rather than when using a die with $\Psi=20^{\circ}$. This difference may be due to the larger contact area between the sample and the die walls for the die with the sharp corner. However, it is readily concluded that ECAP processing using a die with a channel having a small value of $\Psi$, for example $20^{\circ}$, introduces no additional inhomogeneity into the sample during the ECAP procedure. This finding is not fully consistent with some earlier calculations using finite-element methods where it was predicted that a sharp corner die is preferable to a round corner die in producing a homogeneous shear strain distribution over the crosssectional plane [17]. On the other hand, and consistent with the present results, experiments have shown that a round corner die with $\Psi=28^{\circ}$ tends to produce a more homogeneous structure [11].

Although it is possible that different results may be obtained under varying experimental conditions, depending on additional factors such as frictional effects, nevertheless the present conclusion that a small value of $\Psi$ has an insignificant effect on the level of homogeneity is very significant for a practical reason. It is essentially impossible to fabricate a solid die with a very sharp angle of $\Psi=0^{\circ}$ due to the limitations inherent in the machining process in constructing the die. However, the use of a solid die leads to a more convenient and efficient pressing procedure because it avoids the problems associated with the extrusion of slivers of material between the two parts of the die.. Therefore, using a solid die with an internal angle of $\Psi=20^{\circ}$ appears to be an excellent choice when developing a facility for ECAP processing.

\section{Development of homogeneity as a function of the number of passes, $N$}

Pure Al

Numerous investigations of ECAP have shown that it is necessary to process materials by ECAP up to multiple passes in order to achieve satisfactory ultrafine-grained microstructures. Thus, the development of homogeneity as a function of the number of passes is a critical question in ECAP processing. This question may be examined experimentally by plotting microhardness distributions on the cross-sectional planes, using contour maps of the type shown in Fig. 2, for samples subjected to ECAP through different numbers of passes. Figure 3 shows microhardness maps for pure $\mathrm{Al}$ on the $X$ plane in (a) the as-received condition and after (b) 1 pass, (c) 2 passes, (d) 3 passes, (e) 4 passes and (f) 8 passes using route $B_{C}$ with a die having $\Phi=90^{\circ}$ and $\Psi=20^{\circ}$, where the $Y$ and the $Z$ axes are defined as the directions tangential to the top edge and the side edge of 
Fig. 3 Contour maps showing the Vickers microhardness through the cross-sections of pure aluminum billets (a) in the unpressed condition and after pressing through (b) 1 , (c) 2, (d) 3, (e) 4 and (f) 8 passes of ECAP at room temperature using route $\mathrm{B}_{\mathrm{C}}$

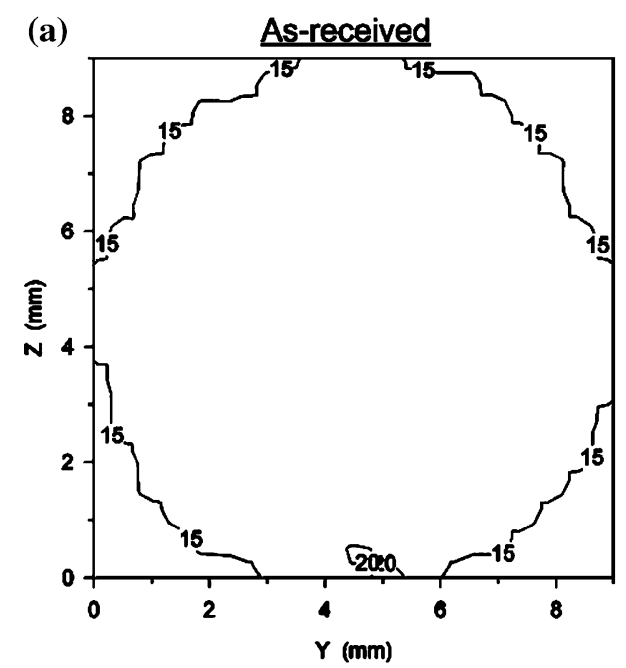

Pure Al
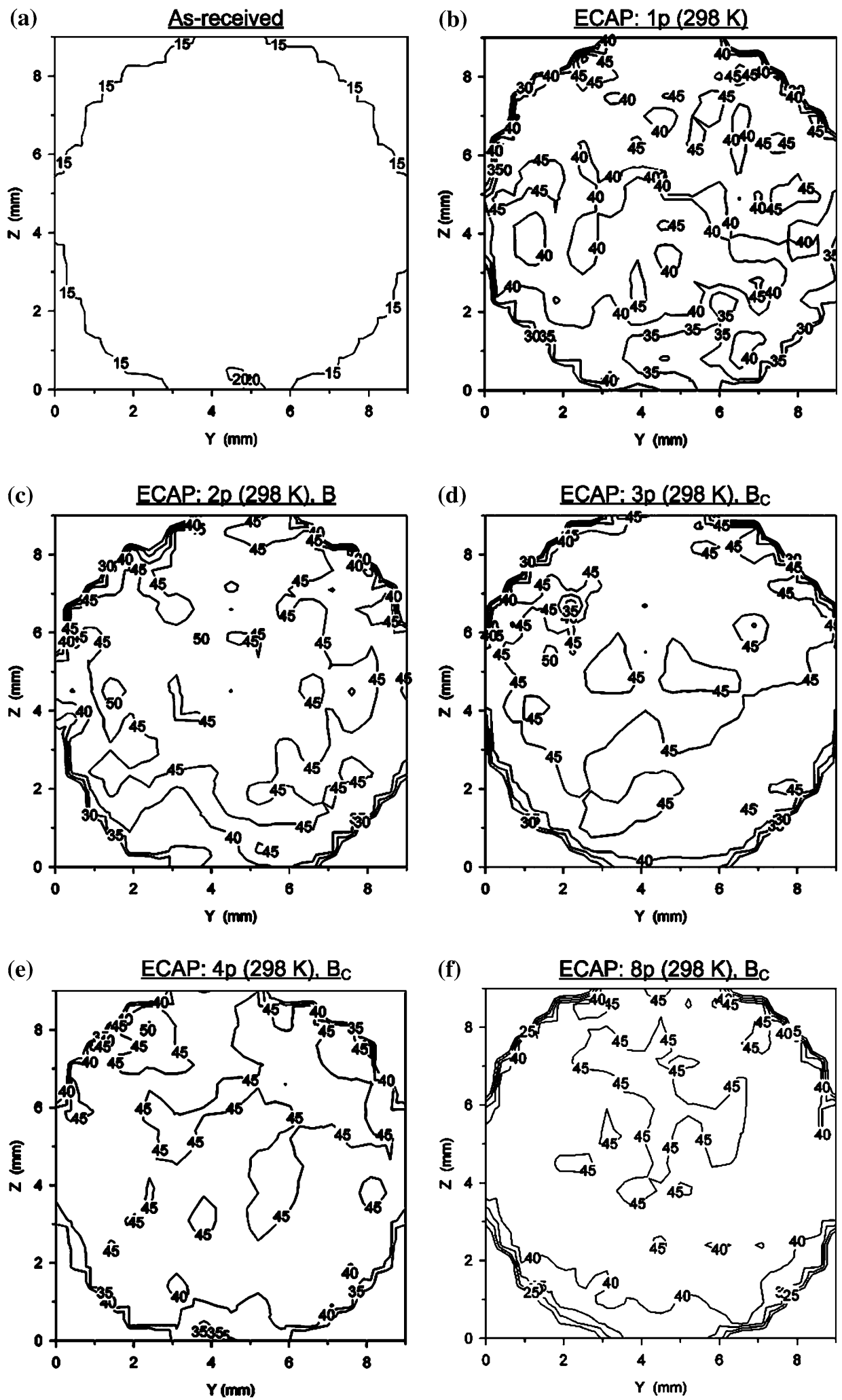

(f)

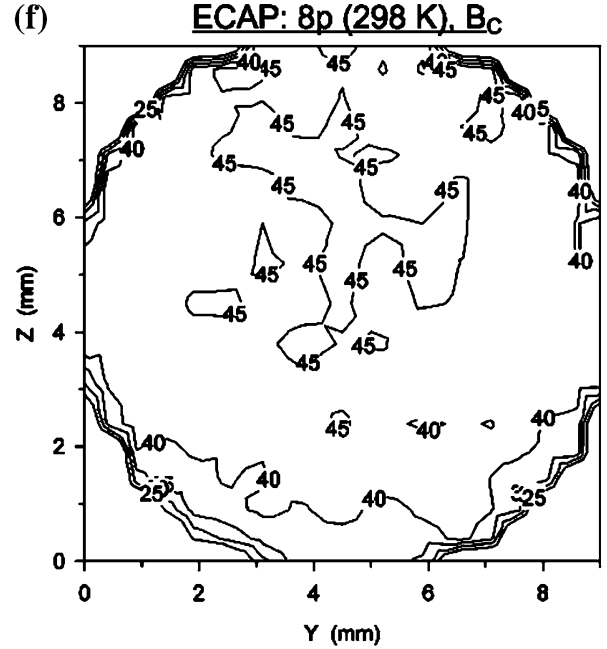

the circular cross-section of the billet at the point of exit from the die, respectively [21]: the precise coordinate system was illustrated earlier in Fig. 1.
It is apparent from Fig. 3 that the microhardness of the pure $\mathrm{Al}$ increases significantly after a single pass of ECAP and this increase occurs over the entire 
Fig. 4 Histograms showing the number fraction of measured values of $\mathrm{Hv}$, in increments of 5, for pure $\mathrm{Al}$ after (a) 1 pass and (b) 4 passes: the vertical lines denote the average values of $\mathrm{Hv}$

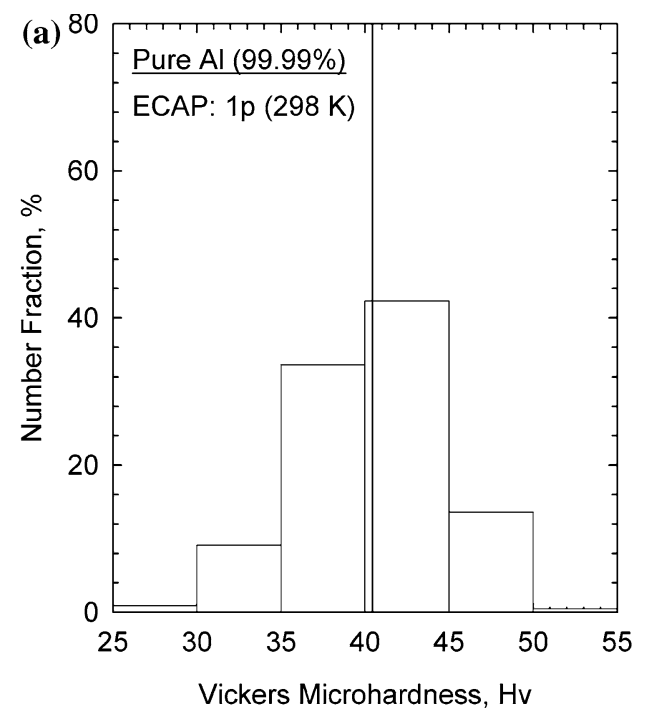

cross-section of the sample. The increase in $\mathrm{Hv}$ continues through subsequent passes and this is due to the well-established reduction in grain size during ECAP since earlier experiments showed a reduction in grain size from $\sim 1 \mathrm{~mm}$ to $\sim 1.3 \mu \mathrm{m}$ after four passes of ECAP at room temperature using a die with $\Phi=90^{\circ}$ and $\Psi=20^{\circ}[22,23]$. However, close inspection of the display after $N=1$ pass shows that the increase in the microhardness is not identical for the entire crosssection and in practice there is a broad region in the vicinity of the lower surface where the values of $\mathrm{Hv}$ are markedly lower than average with values of $\mathrm{Hv} \approx 30$ 35. For the sample after 2 passes of ECAP, the microhardness values continue to increase over the entire cross-section but there remains a small region along the lower surface where the hardness is lower than average. This inhomogeneous region is confined to within a width of $\sim 1 \mathrm{~mm}$ from the bottom surface of the billet after the second pass, thereby demonstrating an increasing improvement in the homogeneity of the microhardness distribution. For the sample pressed through 3 passes, the microhardness values remain almost the same and there is an essentially homogeneous distribution of hardness values but again with some lower values in the vicinity of the bottom surface where these low values are confined to a smaller area than in the sample pressed through 2 passes. A similar situation is observed after 4 and 8 passes and there is a general homogeneity in the hardness values for these two conditions except only in a very narrow region immediately adjacent to the lower surface.

The increasing homogeneity with increasing number of passes may be illustrated directly by plotting histograms showing the number fraction of the individual microhardness values in increments of five on the scale of Hv. The result is shown in Fig. 4 for pure $\mathrm{Al}$ after (a) 1 pass and (b) 4 passes, where the vertical line in each plot denotes the average value of $\mathrm{Hv}$. These histograms show a narrowing of the distribution when the number of passes is increased, thereby confirming the increase in homogeneity at the higher imposed strains.

It is possible to obtain more information about the inhomogeneity adjacent to the lower surface by plotting data as shown in Fig. 5 where the microhardness results are recorded against the distance from the center along a diameter of the billet recorded on the $X$ plane along the $Z$ direction: these datum points span the diameter from the bottom of the billet on the left to the top of the billet on the right, results are shown after

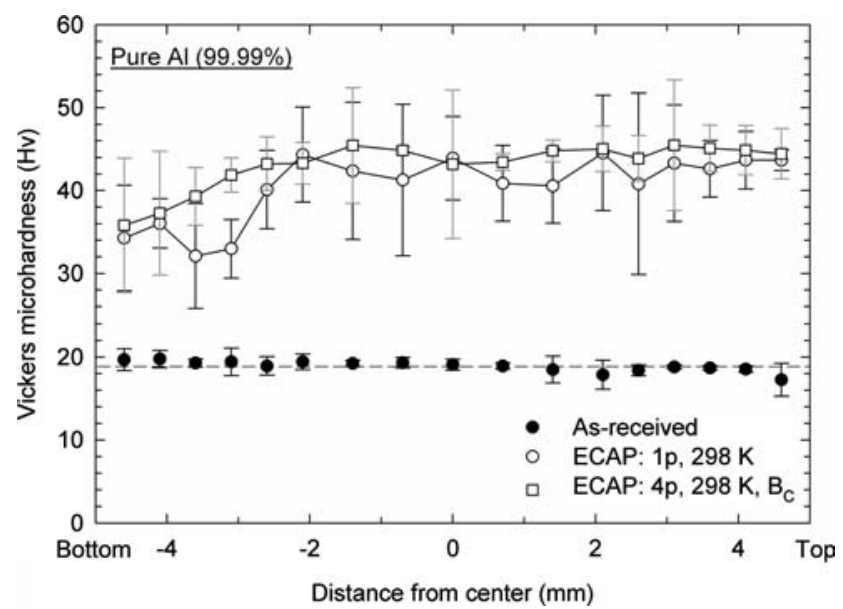

Fig. 5 Values of the Vickers microhardness for pure Al recorded along the $Z$ direction on the cross-sectional plane after processing by ECAP through 1 and 4 passes: the value of $\mathrm{Hv}$ in the unpressed condition is shown by solid points with the broken line representing the average value 
ECAP through 1 and 4 passes, and the lower solid points depict measured data in the as-received and unpressed condition. Each datum point in Fig. 5 is calculated by averaging four adjacent points within a distance of $0.5 \mathrm{~mm}$ and the error bar is calculated using the $95 \%$ confidence value.

It is apparent from Fig. 5 that a single pass of ECAP introduces an inhomogeneous hardness distribution into the cross-section of the billet, especially adjacent to the bottom surface where the hardness is significantly lower than in the other positions. Furthermore, there tend to be larger error bars on the datum points after 1 pass as a consequence of the greater inhomogeneity of this distribution. By contrast, it is apparent that the inhomogeneity is effectively reduced after 4 passes of ECAP through both a general reduction in the magnitude of the error bars and a reduction in the numbers of points having low values of $\mathrm{Hv}$ near the bottom surface. This result again confirms that the homogeneity improves through repetitive pressings although it is important to recognize that a large inhomogeneity is introduced in the first pass.

\section{Al-6061 alloy}

A similar investigation of homogeneity after ECAP was also performed using a commercial Al-6061 alloy containing, in wt $\%, 1.01 \% \mathrm{Mg}, 0.59 \% \mathrm{Si}, 0.37 \% \mathrm{Fe}$, $0.29 \% \mathrm{Cu}, 0.23 \% \mathrm{Cr}$ and $0.20 \% \mathrm{Zn}$ [21]. For comparison purposes, the Al-6061 alloy was fully annealed at $693 \mathrm{~K}$ for $4 \mathrm{~h}$ with a heating and cooling rate of $10 \mathrm{~K} \mathrm{~h}^{-1}$ prior to ECAP to remove the heat treatment effect. The alloy was processed by ECAP at room temperature up to a maximum of 6 passes via route $\mathrm{B}_{\mathrm{C}}$ using a die having $\Phi=90^{\circ}$ and $\Psi=20^{\circ}$ : the pressings were not extended beyond 6 passes to avoid cracking of the billets. An earlier investigation showed this material achieves a grain size of $\sim 0.3 \mu \mathrm{m}$ during ECAP when pressing with an initial grain size of $\sim 50 \mu \mathrm{m}$ [5].

Similar microhardness measurements were undertaken on the cross-sectional surfaces, corresponding to the $X$ plane, and the results are plotted as microhardness contour maps in Fig. 6 for (a) the as-received condition and after (b) 1 pass, (c) 2 passes, (d) 3 passes, (e) 4 passes and (f) 6 passes of ECAP. This material again exhibits excellent homogeneity in the unpressed condition with $\mathrm{Hv} \approx 45$ throughout the cross-section and there is a marked inhomogeneity after a single pass with an average value of $\mathrm{Hv} \approx 78$ but with a large area, covering more than one-half of the cross-section, where the individual values of $\mathrm{Hv}$ are in the range of $\sim 65-75$. As with pure $\mathrm{Al}$, the region having the low $\mathrm{Hv}$ values occurs in the vicinity of the lower surface of the billet. In the subsequent passes, this region with the lower $\mathrm{Hv}$ values gradually reduces in size but nevertheless it remains reasonably significant. On the other hand, unlike pure $\mathrm{Al}$ where the microstructure becomes homogeneous and the hardness saturates at $\mathrm{Hv} \approx 42-44$ after 4 passes, the hardness continues to slowly increase throughout the entire cross-section even after 6 passes.

Figure 7 shows histograms of the number fractions of the microhardness measurements, in increments of $\mathrm{Hv}$ of 5, where the vertical lines again denote the average values and results are shown for (a) 1 pass and (b) 4 passes. Unlike the data for pure $\mathrm{Al}$ given in Fig. 4, there is now a significant increase in the average value of $\mathrm{Hv}$ with increasing imposed strain but there is little or no decrease in the spread of the distributions at least when comparing data obtained after 1 and 4 passes.

The microhardness values are plotted in Fig. 8 against the distance from the center along a diameter on the $X$ plane parallel to the $Z$ axis. Thus, although the homogeneity of the microhardness distribution increases slightly as the number of passes of ECAP increases from 1 to 4, the improvement in the Al-6061 alloy is much less than in pure $\mathrm{Al}$ as shown by the data in Fig. 5. Moreover, the continuing trend of hardness increase shows the hardness for the Al-6061 alloy is not saturated after four passes of ECAP and therefore, unlike the samples of pure $\mathrm{Al}$, it is more difficult to establish an equilibrium microstructure in the Al-6061 alloy.

\section{Discussion}

It can be seen from the above results that both of the experimental materials, pure $\mathrm{Al}$ and an Al-6061 alloy, are capable of achieving a reasonable level of homogeneity after repetitive passes in ECAP although for pure $\mathrm{Al}$ the level of homogeneity is higher and the number of required passes is lower. These results are very encouraging when the ECAP procedure is under consideration for the production of materials for industrial applications. However, it is important to note also that the extent of homogeneity attained in ECAP depends, at least in part, on the hardening characteristics of the material.

Figure 9 shows the values of the Vickers microhardness for pure $\mathrm{Al}$ and the Al-6061 alloy plotted against the number of passes where the value of the average microhardness for each condition was determined by calculating the average of all microhardness measurements on each cross-sectional plane [21]. It is 
apparent from Fig. 9 that the microhardness of both materials increases dramatically after a single pass of ECAP by a factor of approximately $2 \times$. Thereafter, there is a small increase in each additional pass for the Al-6061 alloy up to a maximum value of $\mathrm{Hv} \approx 99$ after 6 passes whereas for pure $\mathrm{Al}$ there is a saturation after
Fig. 6 Contour maps showing the Vickers microhardness through the cross-sections of an Al-6061 alloy (a) in the unpressed condition and after pressing through (b) 1, (c) 2, (d) 3, (e) 4 and (f) 6 passes of ECAP at room temperature using route $\mathrm{B}_{\mathrm{C}}$

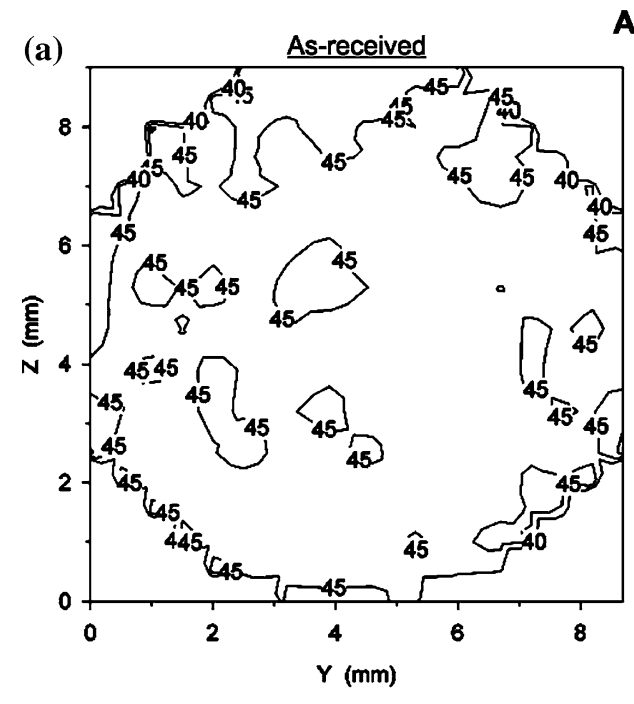

Al-6061

(b)

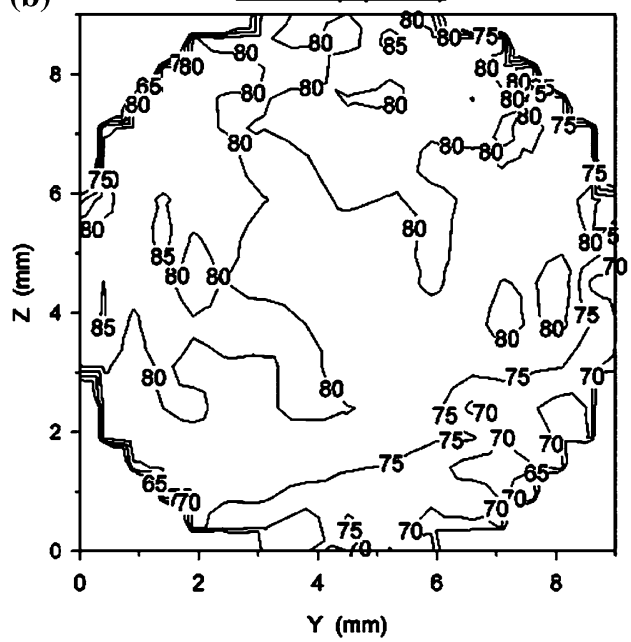

(c)

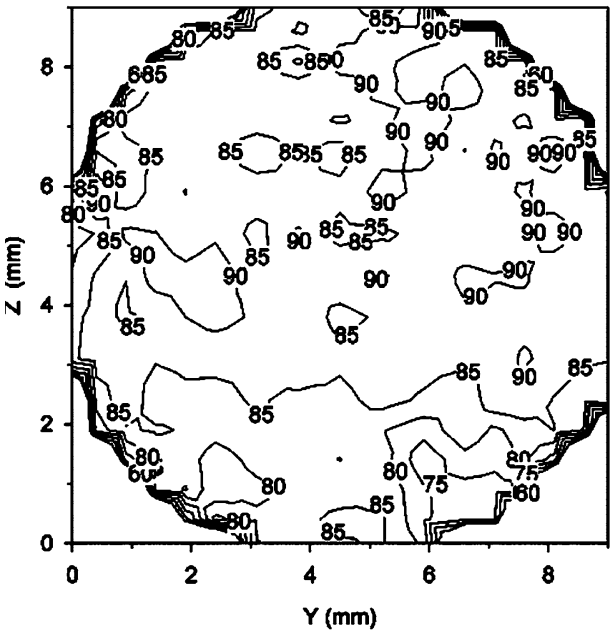

(d)

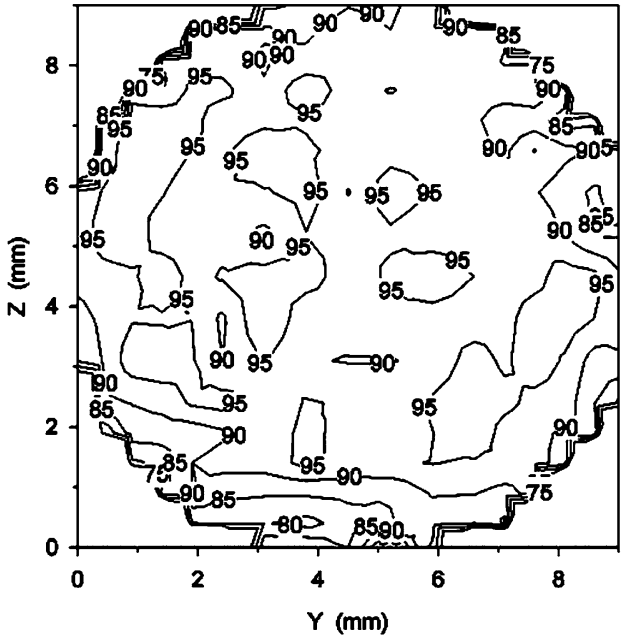

(f)

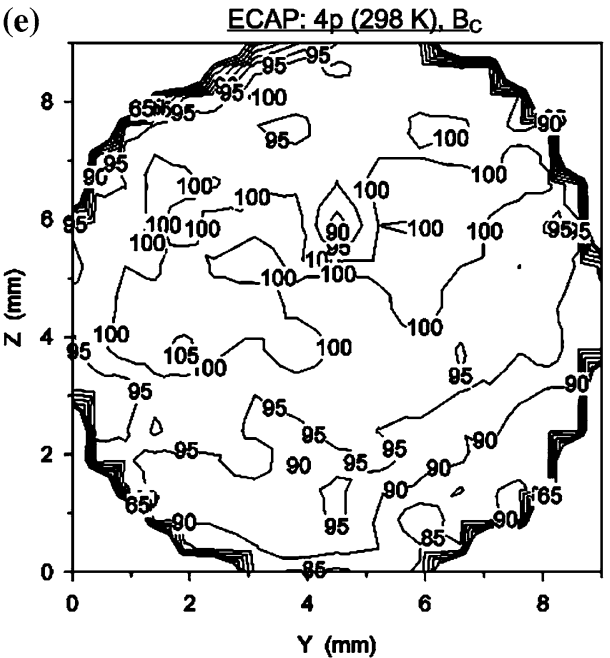

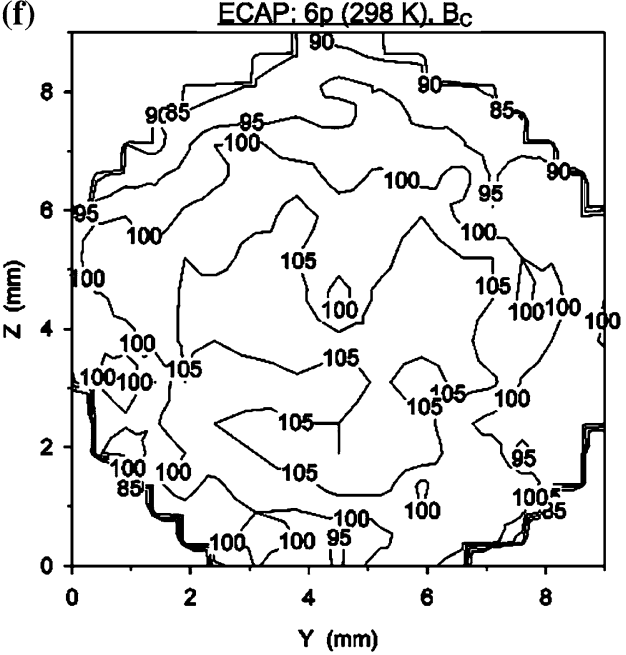


Fig. 7 Histograms showing the number fraction of measured values of $\mathrm{Hv}$, in increments of 5 , for the $\mathrm{Al}$ 6061 alloy after (a) 1 pass and (b) 4 passes: the vertical lines denote the average values of $\mathrm{Hv}$

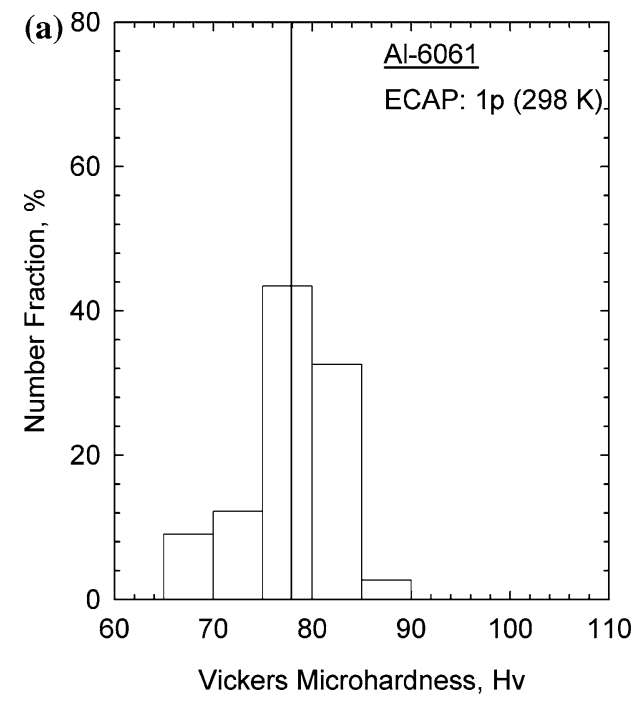

the second pass at a maximum value of $\mathrm{Hv} \approx 44$ and then the hardness remains almost the same in the subsequent passes until the maximum number of 8 passes in the present investigation.

These two different trends are attributed to differences in the material properties including the rate of strain hardening and the rate of recovery. Pure Al has a very high stacking fault energy, a high strain hardening rate and a rapid recovery rate so that it is easy to obtain a high density of dislocations under a fixed applied strain and this favors the development of an equilibrium ultrafine-grained configuration. In addition, pure $\mathrm{Al}$ reaches a straining saturation in a short period of time because there is no other hardening mechanism for pure $\mathrm{Al}$ except dislocation hardening.

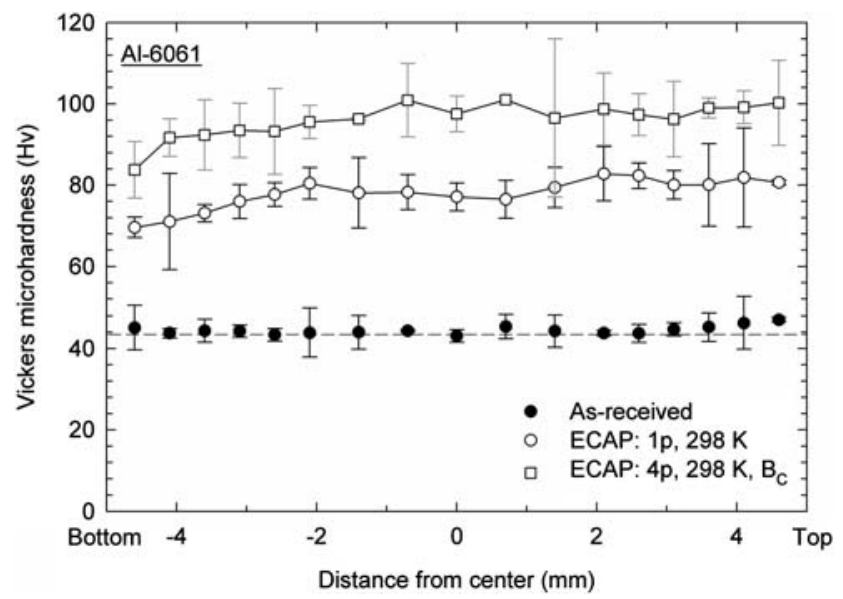

Fig. 8 Values of the Vickers microhardness for Al-6061 alloy recorded along the $Z$ direction on the cross sectional plane after processing by ECAP through 1 and 4 passes: the value of $\mathrm{Hv}$ in the unpressed condition is shown by solid points with the broken line representing the average value
By contrast, the Al-6061 alloy has a lower stacking fault energy, a lower stain hardening rate, a relatively low rate of recovery and, in addition, the alloying elements play a role in providing barriers, in the form of precipitates, for dislocation movement. Therefore, a larger number of passes is required in the Al-6061 alloy in order to achieve a saturation condition and the presence of precipitates provides additional hardening so that the alloy exhibits a relatively long region of strain hardening.

These two trends also provide an explanation for the relatively minor improvement in homogeneity during ECAP of the Al-6061 alloy by comparison with pure Al. Thus, the alloy requires a larger strain in order to achieve an equilibrium array of ultrafine grains and

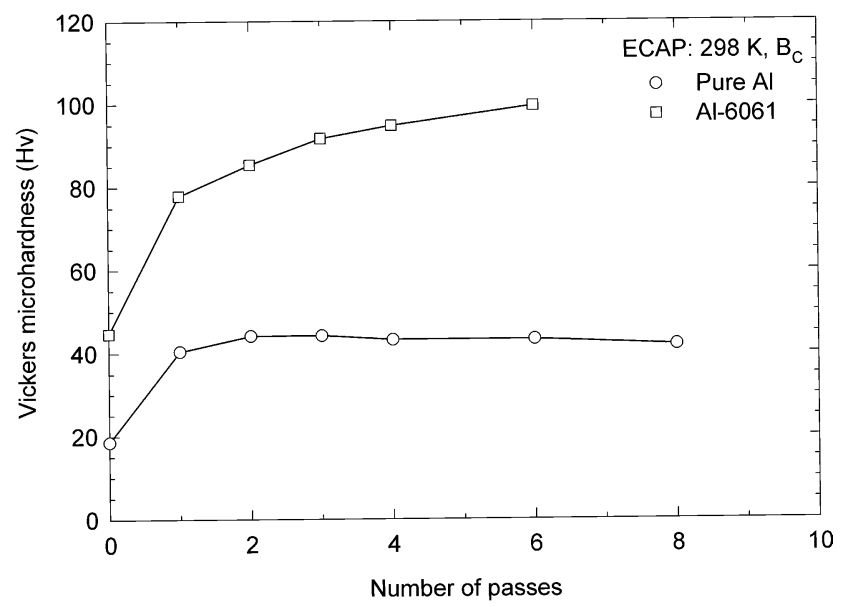

Fig. 9 The average Vickers microhardness, Hv, versus the number of passes in ECAP for pure aluminum and an Al-6061 alloy pressed at room temperature using route $\mathrm{B}_{\mathrm{C}}$ 
therefore the development of homogeneity is slower than in pure $\mathrm{Al}$.

The two trends shown in Fig. 9 for pure $\mathrm{Al}$ and the Al-6061 alloy can be extended to reach conclusions regarding two different types of material: (1) pure metals or materials having high stacking fault energies and (2) alloys or materials having relatively lower stacking fault energies. For the first type of material, homogeneity develops easily with increasing numbers of passes in ECAP and these materials rapidly achieve homogeneity over the entire cross-sectional plane. For the second type of material, homogeneity develops more slowly but nevertheless it may be possible to achieve a reasonably homogeneous microstructure if the material is processed through a sufficiently large number of passes. There are experimental results confirming these conclusions. First, experiments have shown that an increasing number of passes is required in order to achieve reasonably stable and equilibrium microstructures when $\mathrm{Mg}$ is added to aluminum in solid solution [24]. Second, it has been shown that microstructural evolution is very slow in materials such as pure copper where the stacking fault energy is very low [25].

\section{Summary and conclusions}

1. The homogeneity of material processed by ECAP was inspected by taking Vickers microhardness measurements, following a regular rectilinear grid pattern, over the cross-sectional planes of samples processed by ECAP. The results are presented in the form of contour maps depicting the values of the individual microhardness values at each point on the cross-section and thus the hardness distribution over the entire plane.

2. No significant difference in the microhardness distributions of pure $\mathrm{Al}$ was revealed for samples processed by ECAP using a solid die with a corner angle of $\Psi=20^{\circ}$ or with a split die with a corner angle of $\Psi=0^{\circ}$.

3. The hardness distributions for pure $\mathrm{Al}$ and the $\mathrm{Al}$ 6061 alloy both become inhomogeneous after one pass of ECAP and with lower hardness regions in the vicinity of the bottom surfaces of the samples. Both distributions become more homogeneous with additional passes through the ECAP die.
4. Pure $\mathrm{Al}$ achieves an essentially homogeneous hardness distribution after 4 passes of ECAP whereas in the Al-6061 alloy the homogeneity of the hardness distributions gradually improves with increasing numbers of passes in ECAP.

Acknowledgement This work was supported by the National Science Foundation of the United States under Grant No. DMR0243331.

\section{References}

1. Valiev RZ, Islamgaliev RK, Alexandrov IV (2000) Prog Mater Sci 45:103

2. Valiev RZ, Langdon TG (2006) Prog Mater Sci 51:881

3. Xu C, Langdon TG (2003) Scripta Mater 48:1

4. Raab GJ, Valiev RZ, Lowe TC, Zhu YT (2004) Mater Sci Eng A382:30

5. Horita Z, Fujinami T, Nemoto M, Langdon TG (2000) Metall Mater Trans 31A:691

6. Stolyarov VV, Zhu YT, Alexandrov IV, Lowe TC, Valiev RZ (2001) Mater Sci Eng A299:59

7. Valiev RZ, Salimonenko DA, Tsenev NK, Berbon PB, Langdon TG (1997) Scripta Mater 37:1945

8. Komura S. Horita Z, Furukawa M, Nemoto M, Langdon TG (1995) Metall Mater Trans 32A:707

9. Segal VM (1995) Mater Sci Eng A197:157

10. Iwahashi Y, Wang J, Horita Z, Nemoto M, Langdon TG (1996) Scripta Mater 35:143

11. Wu Y, Baker I (1997) Scripta Mater 37:437

12. Nakashima K, Horita Z, Nemoto M, Langdon TG (1998) Acta Mater 46:1589

13. Furukawa M, Iwahashi Y, Horita Z, Nemoto M, Langdon TG (1998) Mater Sci Eng A257:328

14. Shan A, Moon IG, Ko HS, Park JW (1999) Scripta Mater 41:353

15. Semiatin SL, DeLo DP, Shell EB (2000) Acta Mater 48:1841

16. Bowen JR, Gholinia A, Roberts SM, Prangnell PB (2000) Mater Sci Eng A287:87

17. Kim HS, Hong SI, Seo MH (2001) J Mater Res 16:856

18. Kim HS (2001) Mater Sci Eng A315:122

19. Shan A, Moon IG, Park JW (2002) J Mater Proc Tech 122:255

20. Segal VM (2003) Mater Sci Eng A345:36

21. Xu C, Furukawa M, Horita Z, Langdon TG (2005) Mater Sci Eng A398:66

22. Iwahashi Y, Horita Z, Nemoto M, Langdon TG (1997) Acta Mater 45:4733

23. Iwahashi Y, Horita Z, Nemoto M, Langdon TG (1998a) Acta Mater 46:3317

24. Iwahashi Y, Horita Z, Nemoto M, Langdon TG (1998b) Metall Mater Trans 29A:2503

25. Komura S, Horita Z, Nemoto M, Langdon TG (1999) J Mater Res 14:4044 